\title{
Bilateral Retractile Testis: A Possible Risk Factor for Male Infertility
}

\section{Syed Intesar Burni' ${ }^{1}$, Shazia R. Khan², Fareena Khalil Ahmed ${ }^{3}$, Sameera Ali Rizvi ${ }^{*}$, Tazeen Saeed Ali $^{5}$}

\author{
${ }^{1}$ National Research Institute for Fertility Care, Ministry of Health, Karachi, Pakistan \\ ${ }^{2}$ Research Institute of Fertility Care M/O Health, Karachi, Pakistan \\ ${ }^{3}$ Sir Syed College of Medical and Dental Science, Karachi, Pakistan \\ ${ }^{4}$ Department of Public Health, Faculty of Life Sciences, SZABIST, Karachi, Pakistan \\ ${ }^{5}$ School of Nursing and Midwifery, Department of Community Health Sciences, Aga Khan University, Karachi, Pakistan \\ Email: drburneyphd@gmail.com, srknrifc@hotmail.com, fareenazaheer@gmail.com, *dr.sameera.rizvi@szabist.edu.pk, \\ tazeen.ali@aku.edu
}

How to cite this paper: Burni, S.I., Khan, S.R., Ahmed, F.K., Rizvi, S.A. and Ali, T.S. (2022) Bilateral Retractile Testis: A Possible Risk Factor for Male Infertility. Advances in Sexual Medicine, 12, 9-17.

https://doi.org/10.4236/asm.2022.121002

Received: September 21, 2019

Accepted: December 6, 2021

Published: December 9, 2021

Copyright $\odot 2022$ by author(s) and Scientific Research Publishing Inc. This work is licensed under the Creative Commons Attribution International License (CC BY 4.0).

http://creativecommons.org/licenses/by/4.0/

\begin{abstract}
Healthy youth is an asset and strength for economic and social growth of any society. Developmental changes during puberty of youngsters need proper guidance to avoid future physical, physiological and psychological ailments. Bilateral Retractile Testis (BRT) is a health problem if remains unnoticed till adolescence can lead to tribulations. BRT may affect testicular parenchyma and spermatogenesis. Cremasteric muscles (muscles attached with testes) pull the testes up into groin so it randomly moves up and down and do not reside in its natural pouch always. It has been a controversial issue in male infertility as retraction may affect infertility. Objective: To estimate the prevalence of male infertility among patients with Bilateral Retractile Testis. Methodology: A total of 200 male patients were enrolled after the power calculation, with different reproductive health problems between the age of 18 - 40 years during the year 2016 at Reproductive health clinic Jinnah Post Graduate Medical Center (JPMC), Karachi. 25 male patients were reported with infertility and BRT. The data was collected using self-developed questionnaire including outdoor patients' physical check-up, manual testicular examination as size and shape were done. Patient height, weight, blood pressure, their lifestyle, and dressing regarding wearing tight jeans habits were asked. Semen analysis was carried out showing abnormality in sperm count, motility or morphology and entered and analysed in the SPSS version 10. Means and percentages were calculated. Result: Out of 200 male infertile patients, a total of 25 (12.5\%) patients with a diagnosis of BRT were found in the sample with the mean age of 29 years. Moreover, it was identified that those having BRT also have low motility of the sperms. Based on the results it was concluded that
\end{abstract}


BRT is a possible cause of male infertility in Pakistani population. Conclusion: BRT is a possible risk factor to affect sperm motility and low sperm motility can lead to male infertility. The study estimates the prevalence of $12.5 \%$ among our sampled men.

\section{Keywords}

Bilateral Retractile Testis, Male Infertility, Lifestyle, Karachi

\section{Introduction}

Reproductive health is defined as a state of physical, mental and social well-being in all matters relating to the reproductive system, at all stages of life [1]. Improving the sexual and reproductive health of young people is a global priority [2]. Reproductive health problems have silent sporadic growth in our society due to poverty and illiteracy. Unawareness of pubertal developmental changes can lead a youngster towards physical, physiological and psychological ailments [3]. Discussions about reproductive health problems are a dilemma.

One emerging reproductive health problem is Bilateral Retractile Testis (BRT) [4] which is a minor, resolved problem even in childhood in developed countries whereas a major, unresolved issue in our society. Parents either ignore or misunderstand pendulous like testicular retraction which particularly affects sperm motility [5].

Between the $28^{\text {th }}$ and $35^{\text {th }}$ week of gestation, the gubernaculums migrate into scrotum and create space for testes to descend [6]. In normal development, the testes have followed the gubernaculums downwards into scrotum by the time the baby is born. The normal pattern may be interrupted by several possible factors including inadequate androgen (male hormone) secretion, structural abnormalities in boys' genitalia and defective nerves in the genital region [7].

Several research studies have shown that lifestyle factors like smoking and tobacco are associated with male infertility [8]. A study done on quality of life of males has been reported that the type of clothing a man chooses to wear, i.e. tight fitting underwear and pants may have effects on his reproductive health [9].

The present study indicates that Bilateral Retractile Testis is a possible risk factor for infertility as retraction has effects on sperm motility and aims to estimate the prevalence of male infertility among patients with Bilateral Retractile Testis between the age of 18 - 40 years in Karachi, Pakistan.

\section{Materials and Methods}

\subsection{Study Design}

A hospital based cross-sectional study was conducted to assess the status of BRT and infertility among male patients. Assessment of BRT and infertility was made 
at the same pint in time. This hospital provides services to all men from socioeconomically different areas of Karachi.

\subsection{Population}

In the present study 200 male patients between the age of 18 - 40 years were enrolled with diagnosed reproductive health problems, during the period of January to July 2016, at Reproductive Health Clinic, Jinnah Post Graduate Medical Centre (JPMC), Karachi. The patients attended the clinic with the compliant of infertility. Their seminal fluid was assessed for sperm motility. All the patients were provided with simple written and explained instructions about the collection of seminal fluid.

\subsection{Sampling}

The study was carried out on male patients who were diagnosed as a case of infertility by the physicians after they met the definition of infertility i.e. twelve months of unprotected intercourse not leading to conception [10]. Patients were recruited by non-random, convenience sampling method. Male patients who refused to give consent, had been married for less than one year, had a past history of testicular surgery or hormone therapy or cryptorchism were not included in this study. Patients who had other proved aetiology of male infertility were also excluded.

\subsection{Sample Size}

We calculated the sample size with the assumptions of expected frequency of $25 \%$, with the bound of error of $5 \%$, and Confidence interval of $95 \%$ we needed the sample of 173 , to ensure the response rate, and we collected the data from 200 participants.

\subsection{Data Collection}

Information about reproductive health of these men was collected by interviews and physical examinations. Laboratory tests were also carried out for the entire sample. In the reproductive health clinic detailed history of patient was taken with their consent.

Data collection was carried out by trained physicians of the study team. Information about patient's socio-demographic factors such as age, ethnicity, occupation, residence were asked directly from the patient. Age and address of the patient were verified from his National Identity Card. He was also asked about his number of marriages and duration of marriage. Patients were also asked about their dressing habits especially regarding wearing tight jeans. Information about their smoking status was also noted. The detailed physical examination of patients of genitalia was carried out by the trained male doctor.

The clinical examination of external genitalia included the size and shape of testicles, scrotum and penis. After acclimatization of patient with environment 
the testicular ascent was noted in lying position as well as upright position. Semen analysis of patient was carried out focusing on sperm; count, motility, morphology and presence of pus cells. Signs and symptoms of a retractile testicle included:

- The testicle may be moved by hand from the groin into the scrotum and won't immediately retreat to the groin.

- The testicle might spontaneously appear in the scrotum and remain there for a time.

- The testicle might spontaneously disappear again for a time.

\subsection{Data Analysis Plan}

The data were analyzed using Statistical Package for Social Sciences (SPSS) version 10. Frequency, mean and standard deviation were obtained for continuous variables while the categorical variable was assessed by computing frequencies. Excel was used to develop the graph of BRT.

\subsection{Ethical Considerations}

Informed consent was asked from every man before the interview and examination. Ethical approval of the study was obtained from Ethical Review Committee of Reproductive health clinic, Jinnah Post Graduate Medical Centre (JPMC), Karachi.

\section{Results}

A total of 25 patients with a diagnosis of BRT were found out of 200 male infertile patients in the study period $(12.5 \%)$. Our results show that the mean age of men was 29 (Range: 18 - 40) years of the all infertile males. The proportion of infertility among patients coming from Punjab (33.7\%), NWFP (27.4\%) and Karachi city (21.9\%) were found to be higher as compared to patients from Sind (10.05), Afghanistan (2.28\%), Baluchistan (2.28\%) and northern areas of Pakistan $(1.37 \%)$. It was found that sperm motility was lower in patients who had infertility with BRT as compared to patients with infertility without BRT (Figure 1). The mean height of patients was found to be $180 \mathrm{~cm}$. a substantial proportion of infertile men were overweight with BMI between $26-30$ or obese with BMI > 30. The habit of wearing tight jeans was reported by majority of the patients (98\%). Smoking among infertile men was higher as compared to normal men (Table 1).

The sperm motility of infertile men is higher as compared to motility among those patients who were having infertility with BRT (Figure 1).

\section{Discussion}

Infertility is a major health problem. It is inability of a couple on the reproductive age group to achieve pregnancy within one year of unprotected intercourse with the same partner [10]. Infertility is a common problem which affects $14 \%$ - 
Table 1. Socio-demograhic and lifestyle factors among infertility patients at Reproductive Health Clinic during the period of January to July 2016.

\begin{tabular}{cc}
\hline Socio-demograhic and lifestyle factors among men N = 200 & N (percentages) \\
\hline $\begin{array}{c}{ }^{*} \text { Mean age (n years) } \pm \text { SD } \\
\text { Location distribution } \\
\text { Punjab, Pakistan } \\
\text { Karachi, Pakistan }\end{array}$ & $29 \pm 3$ \\
NWFP & $67(33.7 \%)$ \\
Sindh, Pakistan & $44(21.9 \%)$ \\
Baluchistan, Pakistan & $55(27.4 \%)$ \\
Afghanistan & $20(10.05 \%)$ \\
Northern areas of Pakistan & $6(2.28 \%)$ \\
Mean Height with SD & $5(2.28 \%)$ \\
Obesity (BMI > 30) & $3(1.37 \%)$ \\
Habit of wearing tight jeans & $180 \pm 4.0$ \\
Smoking status (n $=200)$ & $80 \%$ \\
Those having BRT & $98 \%$ \\
Those not having BRT & $171(60 \%)$ \\
\hline
\end{tabular}

Mean (Standard Deviation).

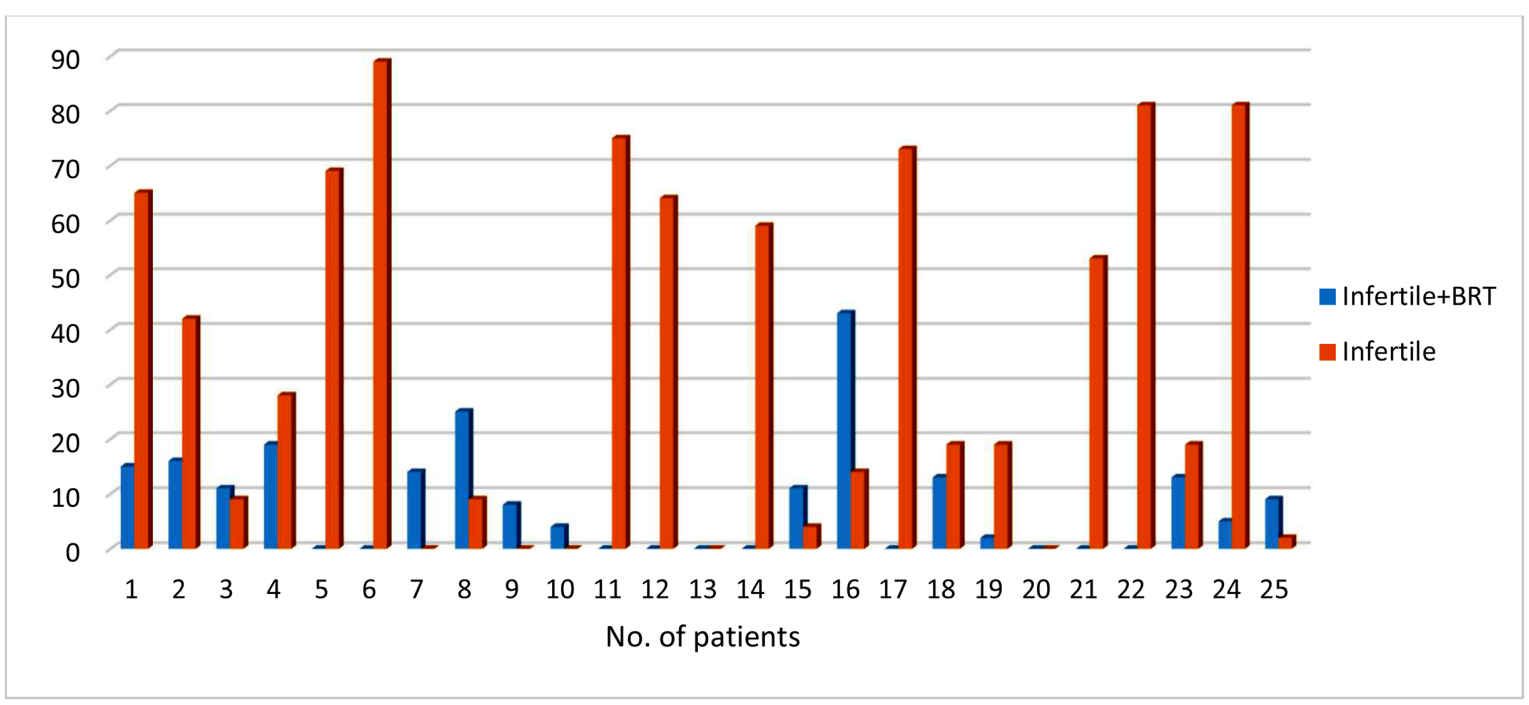

Figure 1. Showing the sperm motility percentage among infertile and infertile + BRT patients.

$26 \%$ couples. BRT is a potential risk factor for infertility [11].

In a study conducted by Dadfar in 2007 [12], a number of 3241 cases were under observation for infertility procedure. Out of them only 26 were found having BRT. This is showing the prevalence of $0.8 \%$; in comparison to our study 25 BRT patients out of 200 were found, which is $12.5 \%$ comparatively a much 
higher number [13]. The other studies conducted in developing countries showing the prevalence of BRT are less in number. Compared to cryptorchidism there remains significantly less studies around retractile testis (RT) [14]. One of the reasons for this might be that RT's impact on spermatogenesis is less understood However, Caroppo et al. study finds that undescended testicle testis (UDT) and RT may share similar quantitative spermatogenetic impairment by sharing similar sperm counts and motilities [15]. Similar to our study, some older studies have suggested BRT as a risk factor for infertility among men [12]. For example, Caucci et al. study supports the prepubertal RT was a risk factor in male infertility, as RT showed poor semen analysis similar to UDT [16]. Another older study conducted by Nistal and Paniague observed how 23 infertile men with BRT had poor sperm count and mosaic lesion [17]. A study by Goede with boys ages under 0.8 to 11.5 years with RT showed that testicular volume of RT is smaller than normal values [18]. This is important as testicular size in adults is directly correlated with testicular function [19]. This is even more concerning as studies have reported reduced number of spermatogonia in tubules in men with reduced testicular volume. Therefore, if there is presence of smaller testicular volume then surgical correction is required. However, other studies show that RT is seen as a variant of normal testis as it descends into the scrotum and thus is similar in testicular volume and childbearing capacity as normal testis [4].

The other factors of BRT in our population are found to the higher weight of men which leads to a sedentary lifestyle and improper eating practices. This is being identified by many other studies that those men who are overweight are the ones having BRT. Studies have shown correlation between obesity and Infertility. A study in Pakistan, showed how fatty tissues can increase the estragon levels which can lead to hypoandrogenemia and altered semen parameter [20]. Obesity can also be a result of decreased physical activity which causes fat deposit in abdominal areas, things and scrotal areas [16]. This leads to heat stress that can increase testicular temperatures that might cause semen impairment [17]. In addition, higher education can lead to sedentary lifestyle as a result of occupations that involve less physical activity. This finding is similar to our study, as the male participants with BRT were of higher weight. Higher education can also be related to increased treatment seeking behaviour [17].

Another possible cause of heat stress might be from constrictive clothing such as tight underwear or jeans. Studies have suggested that tight-fitting, thermally insulating clothing might have an adverse effect on the spermatogenesis which requires the testicles to be at lower temperature than body core [21].

Smoking and tobacco use has also been shown as a common practice. Studies have shown that lifestyle factors such as cigarette smoking, alcohol and drug consumption, physiological stress and diet can have a potential impact on sperm quality [22]. Similar to what our study has demonstrated, many researchers have identified smoking as a factor for sperm parameters. Therefore, maintaining a 
healthy lifestyle can help in decreasing infertility.

Holistically these factors point towards lack of awareness about infertility and health lifestyle; the main reason behind this can be low education and low socioeconomic conditions. Families with low educational attainment and low income might be less likely to seek treatment for BRT due to lack of awareness of BRT and lack financial resources to seek care. For example, a study conducted in USA showed that boys with cryptorchidism has delayed referral for treatment due to poor education of families and lack of routine testicular examinations by healthcare providers [23].

Another study conducted in Pakistan, saw lack of correct knowledge around infertility and participants with lower levels of education had stronger beliefs in evil forces and supernatural powers as causes of infertility [24].

Some of participants would seek alternative medicine such as consulting with Hakeems, and pirs [24]. In comparison, those participants with higher level of education knew there was medical treatment available and would only seek alternative treatment, if allopathic treatments did not work [24]. Additionally, many of the studies in developed countries that observed routine physical checkup of boys, resulted in early treatment of BRT during adolescence and this reduced adult BRT. In our study, however lack of treatment for BRT in adolescent can lead to BRT in adulthood.

Gaps in knowledge about BRT also result from the fact that majority of the infertility studies explore female infertility and not male infertility.

\section{Conclusion}

BRT is a possible risk factor to affect sperm motility by affecting spermatogenesis. Low sperm motility leads towards infertility in males.

\section{Recommendations}

1) All new-born boys should get examined by a qualified paediatrician. In village or town health attendants should be trained for this purpose.

2) It is recommended for all boys even with normal testicle position to learn self-examination during adolescence so they can detect any medical problem associated with their future fertility.

3) All boys/males who had corrective surgery for retractile testis should undergo follow-ups by urologist periodically.

4) A couple before marriage should have some sessions with reproductive health experts for their future marital and parental life regarding their reproductive health.

5) Men should be counselled about the hazards of wearing of tight clothing.

\section{Conflicts of Interest}

The authors declare no conflicts of interest regarding the publication of this paper. 


\section{References}

[1] United Nations Population Fund (n.d.) Sexual \& Reproductive Health. https://www.unfpa.org/sexual-reproductive-health\#readmore-expand

[2] World Health Organization (2021) International Youth Day 2021: Quality Data Crucial for Improving Adolescents' Health and Well-Being in Countries across the World. World Health Organization, Geneva.

[3] Dyer, S., Lombard, C. and Van der Spuy, Z. (2009) Psychological Distress among Men Suffering from Couple Infertility in South Africa: A Quantitative Assessment. Human Reproduction, 24, 2821-2826. https://doi.org/10.1093/humrep/dep278

[4] Anderson, K.M., Costa, S.F., Sampaio, F.J.B. and Favorito, L.A. (2016) Do Retractile Testes Have Anatomical Anomalies? International Brazilian Journal of Urology, 42, 803-809. https://doi.org/10.1590/S1677-5538.IBJU.2015.0538

[5] Sharma, A., Minhas, S., Dhillo, W.S. and Jayasena, C.N. (2021) Male Infertility Due to Testicular Disorders. The Journal of Clinical Endocrinology \& Metabolism, 106, e442-e459. https://doi.org/10.1210/clinem/dgaa781

[6] Nistal, M. and Paniagua, R. (2008) Non-Neoplastic Diseases of the Testis. In: Bostwick, D.G. and Cheng, L., Eds., Urologic Surgical Pathology, Mosby, Maryland Heights, 614-755. https://doi.org/10.1016/B978-0-323-01970-5.50014-2

[7] Docimo, S.G., Silver, R.I. and Cromie, W. (2000) The Undescended Testicle: Diagnosis and Management. American Academy of Family Physicians, 62, 2037-2044, 2047-2048.

[8] Bundhun, P.K., Janoo, G., Bhurtu, A., Teeluck, A.R., Zafooruddin, M., Soogund, S., Pursun, M. and Huang, F. (2019) Tobacco Smoking and Semen Quality in Infertile Males: A Systematic Review and Meta-Analysis. BMC Public Health, 19, Article No. 36. https://doi.org/10.1186/s12889-018-6319-3

[9] Ilacqua, A., Izzo, G., Emerenziani, G.P., Baldari, C. and Aversa, A. (2018) Lifestyle and Fertility: The Influence of Stress and Quality Of Life on Male Fertility. Reproductive Biology and Endocrinology, 16, Article No. 115.

https://doi.org/10.1186/s12958-018-0436-9

[10] World Health Organization (2020, September 14) Infertility.

[11] Dave, S. (2016) A Four-Month-Old Boy with Bilateral Undescended Testes. Canadian Medical Association Journal, 188, 1098-1099.

https://doi.org/10.1503/cmaj.141015

[12] Dadfar, M.R. (2007) Orchidopexy for Retractile Testes in Infertile Men: A Prospective Clinical Study. Urology Journal, 4, 164-168.

[13] Hanerhoff, B.L. and Welliver, C. (2014) Does Early Orchidopexy Improve Fertility? Translational Andrology and Urology, 3, 370-376.

[14] Boisen, K.A., Kaleva, M. and Main, K.M. (2004) Difference in Prevalence of Congenital Cryptorchidism in Infants between Two Nordic Countries. The Lancet, 363, 1264-1269. https://doi.org/10.1016/S0140-6736(04)15998-9

[15] Caroppo, E., Niederberger, C., Elhanbly, S., Schoor, R., Ross, L. and D’Amato, G. (2005) Effect of Cryptorchidism and Retractile Testes on Male Factor Infertility: A Multicenter, Retrospective, Chart Review. Fertility and Sterility, 83, 1581-1584. https://doi.org/10.1016/j.fertnstert.2005.01.088

[16] Caucci, M., Barbatelli, G. and Cinti, S. (1997) The Retractile Testis Can Be a Cause of Adult Infertility. Fertility and Sterility, 68, 1051-1058. https://doi.org/10.1016/S0015-0282(97)00410-X

[17] Nistal, M. and Paniagua, R. (1984) Infertility in Adult Males with Retractile Testes. 
Fertility and Sterility, 41, 395-403. https://doi.org/10.1016/S0015-0282(16)47718-6

[18] Goede, J., Voort-Doedens, L.M., Sijstermans, K. and Hack, W.W.M. (2011) The Volume of Retractile Testes. The Journal of Urology, 186, 2050-2055. https://doi.org/10.1016/j.juro.2011.07.020

[19] Keys, C. and Heloury, Y. (2012) Retractile Testes: A Review of Current Literature. Journal of Pediatric Urology, 8, 2-6. https://doi.org/10.1016/j.jpurol.2011.03.016

[20] Zahid, N., Saleem, S., Azam, I. and Moatter, T. (2015) Association of Obesity with Infertility among Pakistani Men: A Case Control Study. Open Journal of Epidemiology, 5, 204-215. https://doi.org/10.4236/ojepi.2015.53025

[21] Jung, A. and Schill, W.B. (2000) Male Infertility. Current Life Style Could Be Responsible for Infertility. MMW-Fortschritte der Medizin, 142, 31-33.

[22] Durairajanayagam, D. (2019) Lifestyle Causes of Male Infertility. Arab Journal of Urology, 16, 10-20. https://doi.org/10.1016/j.aju.2017.12.004

[23] Jiang, D.D., Acevedo, A.M., Bayne, A., Austin, J.C. and Seideman, C.A. (2019) Factors Associated with Delay in Undescended Testis Referral. Journal of Pediatric Urology, 15, 380.el-380.e6. https://doi.org/10.1016/j.jpurol.2019.03.029

[24] Ali, S., Sophie, R., Imam, A.M., Khan, F., Ali, S.F., Shaikh, A. and Hasnain, S.F. (2011) Knowledge, Perceptions and Myths Regarding Infertility among selected Adult Population in Pakistan: A Cross-Sectional Study. BMC Public Health, 11, Article No. 760. https://doi.org/10.1186/1471-2458-11-760 